\title{
TRIFLUORMETHANESULFONIC IMIDAZOLIDE
}

A CONVENIENT REAGENT FOR INTRODUCING THE TRIFLATE GROUP *

\author{
F.EFFENBERGER and K.E.MACK
}

Institut für Organische Chemie der Universität Stuttgart (Received in UK 23 July 1970; accepted for publication 27 August 1970)

In all investigations of solvolysis reactions, the trifluormetbanesulfonate (triflate) anion has proven the best leaving group. (1-3) While a series of alkyl and alkengl triflates have already been synthesized, little is known about aryl triflates the solvolysis of which we are investigating. So far, only phenyl and pmethoxy-phenyl trifluormethanesulfonate have been reported on in the literature. (3) No experimental data are given, though, for the synthesis following the thallium salt method. 2-Naphtbyl triflate bas been synthesized from B-naphthol with trifluormethanesulfonic acid anhydride, 1.(4) The instability of the anbydride, however, limits the general applicability of this reaction.

We bave modified the imidazolide procedure developed by STAAB et al. (5) to afford smooth introduction of the triflate group.

2

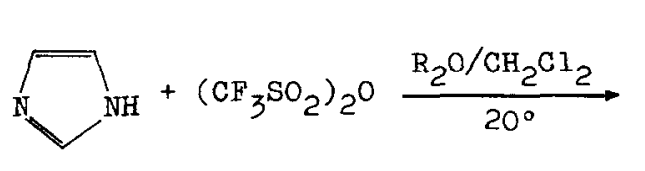

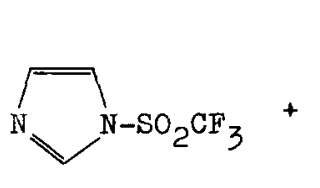

2

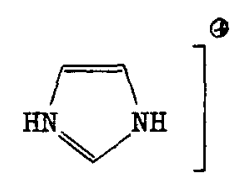
$\mathrm{CF}_{3} \mathrm{SO}_{3}{ }^{\ominus}$

Upon reaction of imidazole with $1^{* *}$, trifluormethanesulfonic imidazolide, 2 , is formed in good gield; the acid liberated in the course of the reaction is removed as the imidazolium salt 3 .

Fractional destillation affords the imidazolide 2, a liquid of pleasant odour and rather low boiling point (b.p. $\left.1146^{\circ}\right)$, in pure form; in a closed vessel, it may be stored indefinitely. 
With phenols, 2 reacts to give aryl triflates 4. The gields of pure 4 are given below. Since all preparations were carried out on a small scale, higher yields are to be expected for laboratory scale experiments. Addition of catalytic amounts of phenolate results in improved Jields within shorter reaction times.

\begin{tabular}{|c|c|c|c|c|}
\hline \multicolumn{2}{|c|}{$\mathrm{Ar}-\mathrm{OH}+2 \underline{\mathrm{Ar}-\mathrm{O}^{\ominus}}$} & \multicolumn{2}{|c|}{$\begin{array}{c}\mathrm{Ar}-\mathrm{O}-\mathrm{SO}_{2} \mathrm{CF}_{3} \\
4 \mathrm{a}-\bullet\end{array}$} & N \\
\hline & Ar & yield & & \\
\hline 4a & phenyl & $68 \%$ & b.p. 50 & $99-100^{\circ}$ \\
\hline $4 \mathrm{~b}$ & p-cresyl & $76 \%$ & b.p. 50 & $115^{\circ}$ \\
\hline $4 c$ & p-chloro-phenyl & $71 \%$ & $b \cdot p \cdot 45$ & $117^{\circ}$ \\
\hline $4 d$ & p-nitro-phengl & $73 \%$ & $\mathrm{~m} \cdot \mathrm{p}$. & $53^{\circ}$ \\
\hline $4 e$ & B-naphthyl & $70 \%$ & $\mathrm{~m} . \mathrm{p}$. & $31-32^{\circ}$ \\
\hline
\end{tabular}

Trifluormethanesulfonic imidazolide, 2: $33.9 \mathrm{~g}$ of 1 in $30 \mathrm{ml}$ abs. ether are added dropwise to a solution of $21.7 \mathrm{~g}$ imidazole in $300 \mathrm{ml}$ abs. $\mathrm{CH}_{2} \mathrm{Cl}_{2}\left(30 \mathrm{~min}, 20^{\circ}\right)$. The reaction mixture is kept at $-20^{\circ}$ for 12 bours, the 1midazolium salt which precipitates is filtered off, and the filtrate fractionated: $20.4 \mathrm{~g} 2$ (85\%); b.p. $1146^{\circ}$, m.p. $22^{\circ} ; n_{D}{ }^{25} 1.4148$.

Phenyl trifluormethanesulfonate, $4 \mathrm{a}: 2.0 \mathrm{~g} \mathrm{2}, 0.94 \mathrm{~g}$ phenol and $0.03 \mathrm{~g}$ phenolate are heated for 2 hours to $80-90^{\circ}$. Imidazole which immediately precipitates upon addition of $5 \mathrm{ml}$ abs. ether to the cooled reaction mixture is filtered off, the ethereal solution is washed with $5 \mathrm{ml} 2 \mathrm{~N} \mathrm{NaOH}$, dried over $\mathrm{MgSO}_{4}$ and fractionated: 1.54 g $4 a(68 \%) ;$ b.p. $6099-100^{\circ}$.

* We gratefulig acknowledge the support of this work by the Deutsche Forschungsgemeinschaft and the Fonds der Chemischen Industrie.

** Dr.R.I.HANSEN of the Minnesota Mining and Manufacturing Co. kindly provided us with a sample of barium trifluormethanesulfonate.

(1) R.L.HANSEN, J.OrE.Chem. 30, 4322 (1965).

(2) A.STREITWIESER, JR., C.I.WILKINS and E.KIELMANN, J.Am.chem.Soc. 90, 1598 (1968).

(3) TAH MUN SU, W.F.SIIWINSKI and P.V.R.SCHLEYER, J.Am.chem.Soc. 21, 5386 (1969).

(4) J.BURDON and U.C.R.McLOUGHLIN, Tetrahedron 21, 1 (1965).

(5) H.A.STAAB and K.WENDEL, Chem.Ber. 93, 2902 (1960). 